\title{
revista.tradumàtica
}

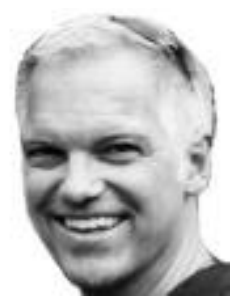

\section{Future (and not-so-future) trends in the teaching of translation technology}

Frank Austermuehl Director, Centre for Translation Studies and Interpreting

The University of Auckland

f.austermuehl@auckland.ac.nz

\section{ABStRact}

This paper proposes an approach to teaching translation technology that focuses less on exposing students to ever more types of CAT tools than on two sets of metacompetences-revision skills and documentary research skills-and on the technologies that allow students to optimize these skills.

Keywords: Documentary research; revising; post-editing; machine translation; Web as Corpus; EN 15038

Resumen (Futuras (y no tan futuras) tendencias en la enseñanza de las tecnologías de la traducción)

Este artículo propone una aproximación a la enseñanza de las tecnologías de la traducción que no se centra en la presentación a los estudiantes de más herramientas TAO, sino en el trabajo en torno a dos conjuntos de meta-competencias - las destrezas de revisión y las destrezas de búsqueda documental- y las tecnologías que permiten a los estudiantes optimizar estas destrezas.

Palabras clave: Búsqueda documental; revisión; postedición; traducción automática; Web como corpus; EN 15038

Resum (Futures (i no tan futures) tendències en l'ensenyament de les tecnologies de la traducció)

Aquest article proposa una aproximació a l'ensenyament de les tecnologies de la traducció que no està centrada en la presentació als estudiants de més eines TAO, sinó en el treball al voltant de dos conjunts de metacompetències - les destreses de revisió i les destreses de cerca documental- i les tecnologies que permeten als estudiants optimitzar aquestes destreses.

Paraules clau: Cerca documental; revisió; postedició; traducció automàtica; Web com a corpus; EN 15038

\section{Introduction}

A commonplace observation at translation conferences-one often voiced by industry representatives-is that Translation Studies, as a whole, has been slow to adapt didactically to the integration of new technologies into professional translation process. While our discipline has produced isolated visionary attempts at pre-empting market pressure on translator training (see, for example, Kenny and Way's 2001 discussion of CAT vs. MT teaching, O'Brien's 2002 proposal for contents of a post-editing course, or Enríquez Raído and Austermuehl's 2003 distinction between knowledge and productivity tools), we as a 
discipline are usually lagging behind industry developments. The reasons for this "institutional belatedness" (Pym, 2011) include the following:

i) Technology solutions such as translation memory or statistical machine translation systems are developed either outside universities, i.e. in translation companies or companies with translation needs, or within non-translation university departments (usually Artificial Intelligence or Computational Linguistics) (cf. Way 2009; Doherty, Kenny, and Way 2012).

ii) There is not enough research, in particular empirical research, on these tools, their impact on translation processes, products, and producers, and hence more often than not no solid basis for developing courses and course contents (cf. Pym, 2012).

iii) Many translator trainers do not have the professional and/or technological expertise to promptly and properly implement translation technologies into their teaching.

iv) There is so much else to teach, and often not enough time even for that (see below).

Other reasons include slow institutional processes in allowing universities to offer new courses or degree programs; centralized control over degree design; a lack of access to funding, tools, and industry partners; attitudes of teachers and students (see the notion of self-efficacy among translators as discussed in Atkinson 2011); the lack of technical knowledge among students, or infrastructure issues (see Doherty and Moorkens 2013).

Yet, maybe, lagging behind technological developments is not such a bad thing in and by itself. After all, such an implementation gap allows if not for detailed empirical studies then at least for a critical reflection of the different tools and their impact on translators, which in turn might lead to teaching and learning that is less a knee-jerk reaction to market developments than a sustainable and critical discussion of the relevance and impact of the various tools.

Also, and despite the hype created by the language industry about every new solution that reaches the market, there really has not been a conceptually new tool since, possibly, the advent of software localization tools. (MT might be changing the way translation agencies do their business but the concept has of course been around for a long time and even younger approaches, such as example-based MT, EBMT, and statistical MT, SMT, have been used since the 1980s, albeit with a much smaller data base). The way tools are accessed has changed -in many cases moving to a software as service (SaaS), or cloud model-as has their level of sophistication, but the kind of support they give to translators, the sort of tasks they carry out, really have not. Even more so, with the success of the phrase-based statistical machine translation paradigm (Koehn 2010, cf. Way 2009; and Way and Hearne 2011) and the increasing use of the Web as Corpus, especially for ad-hoc terminography (cf. Bowker 2011 and Austermuehl 2012), we might actually see the disappearance of certain toolstranslation memories and, maybe, and more problematically, terminology databases, respectively-that have dominated the discussion of translation technology for the past two decades (see Koehn 2009, for a description of a system called Caitra, in which the scaled use of information stored in a phrase-based SMT system renders separate translation memories and termbases obsolete).

Thus, knowing what to teach should not be so difficult and surely not as volatile an issue as one might think (knowing how to teach is a whole different matter, though). Looking back at the content of my 2001 Electronic Tools for Translators (which will appear in an "updated" version in 2014, co-authored with Vanessa Enríquez Raído), the tools available to translators (and the skills needed to use them efficiently) are still basically the same. From file management to utilities such as e-mail clients, compression and encryption software, to reference works, terminology databases, translation memory, software localization tools, and MT systems, the tools discussed are all still around, albeit in different, more advanced (and more automated) forms, and often combined within a single suite of programs, or translation 
environment tools (TEnTs, see Zetsche 2007 and 2012). And while there will be new perspectives, such as a stronger focus on the built-in quality assurance and post-editing features of TEnTs, the only really new addition to the book will be a chapter on the notion of crowdsourced or social translation, which represents less of a new tool as defined below than a new way of working together by volunteer translators (see De Palma and Kelly 2008, Désilets 2010, and Austermuehl 2011; but see the upcoming conference Collaborative Translations: Old Challenges and New Scenarios [http://www.ille.uha.fr/colloquesseminaires/Colloques/Coll-traduire-a-plusieurs] on just how new this phenomenon is). Of course, there are a lot of topics that could be added, both at the lower, but clearly not irrelevant end of the tool/skills sets such as using Microsoft Word's language tools or its reviewing features, and at the top-end, such as project management software or even MT development/programing. It is, I guess, all a matter of how much you want and need to know for a given job and how much time you have. And that in turns depends a lot on the way translation programs are structured.

\section{What to teach when}

Before discussing two different approaches to the teaching of translation technology-a maximalist one and a minimalist one-it is important to stress that any current discussion of how to integrate the teaching of translation technology solutions, or tools, into the training of future translators needs to acknowledge in particular the impact that recent developments in machine translation (MT), especially in statistical machine translation (SMT) has had, and will continue to have, on the lives of professional translators. As a consequence of the "rise of the machines," translation agencies are shifting to business models that are based upon the use of machine translation systems to produce draft translations on a large scale. Depending on the quality needs of the client, these drafts are then revised by human translators who are often made to bid for these jobs in an online auction (see Austermuehl, 2011). This business model is driven by translation service providers with the financial and technical resources to significantly adapt publicly available MT engines such as MOSES and/or to develop their own MT systems, including hybrid solutions (see Thicke, 2011). It is also realistic to assume that these providers, and not individual translators, are the main beneficiaries of this new model.

The success of data-driven statistical machine translation systems, which has as much to do with increased technical capabilities as with decreased user expectations, is changing the very nature of translation. Along with that change comes the need to "rethink, yet again, the basic configuration of our training programs" (Pym, 2012). As I will explain below, this rethinking does not necessarily have to be a bad thing, and in some ways it might not even be so much a new orientation as a return to pre-CAT (computer-assisted translation) times. The following discussion will be based on the assumption that MT is here to stay and that it will become a major, maybe even dominant approach of doing business in and with translation. I am also assuming, or rather proposing, that translators will/should be involved in so-called full editing of MT output, i.e. their involvement aims at ensuring target texts of publishable quality.

In this article, I will be focusing on what types of translation tools to teach and when to teach them. While I will also be briefly referring to how to teach translation tools, this aspect is discussed in greater details in some of the other contributions to this issue. In answering my two $\mathrm{W}$ questions, the what and when, it is first of all important to take into consideration the institutional and curricular circumstances of translation programs in general. Given the different natures and realities of these programs, I will discuss both a maximalist and a minimalist approach to teaching translation tools.

Which brings me to the question of what types of translation tools-tool is defined here as "something (as an instrument or apparatus) used in performing an operation or necessary in the practice of a vocation or profession" (Merriam Webster) or as "anything used as a means 
of performing an operation or achieving an end" (Collins)—should be taught in a translation program. As indicated above, the answer to this question depends a lot on the educational frameworks within which translation technology solutions are taught.

If you are teaching as part of a translator training institution with a two-cycle setup (i.e. where translation is taught both on an undergraduate and a graduate level), students who decide to complete both cycles will have a maximum of five years of training (either three or four years towards a Bachelor, and one or two years for a Masters); a default situation for European programs but also visible in, for example, China (although here the more recent two-year MTI can also be taken independently of previous undergraduate studies in translation). Anecdotal evidence from programs in Germany, Spain, or China seems to suggest that a majority of students enrolling in an undergraduate degree seem indeed to enroll in a Masters as well (there is more research needed on the study and career choices of our BA graduates). Yet, even if students opt only for an undergraduate degree, they will in general still have three or four years of translator training. This should leave plenty of time to integrate courses on all kinds of translation technology and to teach course contents outlined by the OPTIMALE project (www.translator-training.eu), or the European Masters of Translation (EMT) consortium (http://ec.europa.eu/dgs/translation/programmes/emt/index_en.htm), or go through the entire table of contents of Jost Zetsche's Translator's Toolbox (http://www.internationalwriters.com/toolbox/). (More advanced aspects such as software localization or A/V translation might need to be left for the second and last cycle of studies). I do not think that you are going to get a lot of translation students to start learning a programming language (see O'Brien 2002), but, heck, you might even have enough time to give that one a try.

In such an "EU" scenario that allows for a comprehensive and in-depth discussion of a large number of tools, challenges arise more from the right sequencing of course contents (cf. Kelly 2005 and 2007) and the overall teaching methodology, including questions on how to overcome the isolation of tool teaching and getting the technology into the translation classroom on a regular basis. Here, researches in translation pedagogy have proposed a number of professionally oriented, project-based and situated approaches that include, for example, simulation and role play (i.e., students becoming terminologists, translators, revisers, or project managers) that emphasize team work and an understanding of production process in the translation industry (see, for example the University of Granada's PATT project [Olvera Lobo et al. 2007] or, with regard to translation teaching in general, González Davies 2004 and Kiraly 2000).

Things do, however, get more tricky if your ability to teach translation technology is restricted to the postgraduate (PG) level, either if you have students enrolling in an MA that come from different subject areas (what we call Quereinsteiger in German) or if you are working in an environment where a one-year or two-year PG degree is the default setting for translator training in general and where teaching in specialized professional translation needs to be balanced with both language teaching and laying a theoretical foundation for translational actions. This is a situation found, for example, in a number of English-speaking countries, including Australia, New Zealand, or the United States. (In light of the obvious challenges of trying to train professional translators in one single year, we are introducing, in 2014, a new two-year MA program as our default program at the University of Auckland.)

In such a complex educational environment (made even more complex by the presence of a multitude of different $A$ and $B$ languages in the classroom), the question of what to teach becomes even more challenging. One approach, which we take in Auckland, is to have a dedicated basic course on CAT tools in the first year of PG training and squeeze in as much as possible, from file management to internet resources to terminology management and translation memory suites. We leave localization and machine translation, including post- 
editing tools, as a specialization for the students' second year of study. In a way, such an approach works (see also Doherty and Moorksen 2013 for the description of a very similar course at Dublin City University), as it provides students with a conceptual and critical overview of and minor practical experience with the main technology solutions. This focus on terminology mining and management and translation memory systems is supported by results from an employer survey carried out by the OPTIMALE project, in which 69 per cent of respondents consider the ability to manage and extract terminology either essential or important, and 76 per cent consider the ability to use translation memory systems either essential or important (OPTIMALE 8-9; but see Lafeber 2012 for seemingly different priorities in intergovernmental organizations). Yet, one wonders how deep the understanding of the different tools and, above all, their impact on the translation process really can be if taught under time and resource constraints, to students of varying degrees of linguistic, technological, and translational competence, and more or less removed from translation practice and theory classes. (Additional self-learning resources are crucial here and they are available, but not for all languages, and their impact depends to a great extent on high levels of self-efficacy among students [Doherty, Kenny, and Way 2012]). And then there is the question whether such a tool-oriented approach is indeed the best use of our and our students' time. The CAT course makes up 25 per cent of the first-year course work, time that, one wonders, might be spent better on additional language acquisition and translation practice classes.

\section{A minimalist approach to teaching translation technology (without really teaching too much technology)}

Not having all the time in the world might be a good thing as it forces you to concentrate on what is really important, on not only the core tools mentioned above but also, and more generally speaking, on the core skills in dealing with translation (technology). So, what three things would I take on my translation technology teaching island? My answer would be 1) revising skills in the target language (ideally, but not necessarily so, the mother tongue); 2) documentation and research skills; and, of course, 3 ) sunscreen. The benefits of sunscreen have been comprehensively explained by Mary Schmich, a writer for the Chicago Tribune (1997), and subsequently internationalized in Buz Luhman's (1998) "Everybody's Free (To Wear Sunscreen)." But what about the first two items on my list?

I see translation as the self-confident production of an independent target text based on a number of information sources, one of which is the source text. This view is also influenced by Hans Vermeer's quote "Übersetzen ist die Verwendung des Verstandenen" (1986, 305). In the context of Vermeer's Skopos theory, translation thus represents a dual, cognitive and pragmatic process of acquiring knowledge about and understanding the source text, and applying said understanding or knowledge in the creation of a new text. Here, exceptional command of one's mother tongue or one's main target language-given that for translations into English, for example, it is often difficult to find native speakers, even for major European languages (see Winter 2012) -and thorough researching skills represent important, if not the most important meta-skills in our field.

Thus both competences are central to my understanding of what translation is-they support both the process of understanding and its usage-and what translator should be able to do well. Furthermore, both sets of skills, which have to be developed over time, also have a significant added value, possibly more so than knowing how to maneuver translation environment tools or project management software or to have acquired specialized subjectarea knowledge, skills that can be acquired more rapidly and, if needed, on the job. These two meta-skill sets are also not restricted to the realm of translation technology-and could be easily taught in non-technology classes. They are multifunctional, transferable skills that are needed in all kinds of translational actions (and non-translational actions as well). Finally, they 
play to our strengths, inasmuch as translators are much better suited in researching multilingual information from any number of domains and producing or optimizing texts, written in different languages, representing different genres and subject areas, than, for example, domain experts or monolingual writers and reviewers would be.

\subsection{Revising is the new translating}

A number of my recent graduates have managed to find permanent in-house jobs-not as translators but as revisers of MT output (often combined with project management duties). The need for revisers is a testament to both the improved quality of MT systems as to their lack of quality, if that makes sense. Given this focus on quality, the following discussion of MT will concentrate on the use of MT systems for dissemination. Here, the goal of the translation is to produce target texts "of publishable quality; not necessarily texts that are actually published, but rather texts that are of that quality" (Hutchins 2005: 8).

As a number of studies have shown (see Austermuehl 2011, for a brief overview), using professional translators to revise and optimize, i.e. to post-edit translations produced by an MT system can lead to significant productivity gains. While, as Pym points out, "the numbers are rough, and perhaps only valid for a handful of subjects, working on a particular text type, under certain conditions, and for a certain kind of quality expectation" (2011), new MT-based business models, in which translation is reduced to the revising of electronically recycled patch-work texts, are already changing the business of translation.

As I mentioned earlier, the acceptance of machine-translated texts, especially post-edited ones, has a lot to do with user expectations and varied needs for quality (or an increased pain threshold for poor quality). Very often, quality in machine translation, even for dissemination purposes, and in translation in general, is based on a "good-enough approach." Similar to language industry norms aimed at reducing errors by controlling the process through which a product is created, quality in MT is often defined as the absence of errors. (In MT circles, the "quality" of MT output is traditionally assessed by machines-a peer review in a way-where automatic quality metrics compare individual, context-less sentences against "ideal" "human" translation. One wonders if we should thus take these metrics, such as BLEU or NIXT, seriously, but see Specia, Raj, and Turchi 2009 or Green, Herr, and Manning 2013 on correlations between machine and human assessment.)

Good enough will be more than good enough for the group of professionals that American economist Herbert Simon (1956) refers to as "satisficers"-professionals adopting "a decision-making strategy that attempts to meet criteria for adequacy, rather than to identify an optimal solution" (http://psychology.wikia.com/wiki/Satisficing). Optimizers, however, committed to "the art of finding the best choice among all choices" (Moyer 2007) - a group with which I would think most translators would self-identify_might enter a collective identity crisis.

The ability to optimize one's own work or the work of a fellow translator has always played a central role in translation and has long been among additional services offered by or career opportunities available to translators (see Mossop 2001). CIUTI, a global network of university translation programs, for example, lists "competence in the native language" as the first of their four key competences that translators and interpreters should have (the others being competence in the foreign language(s), intercultural competence, and translator's competence") (http://www.ciuti.org/about-us/profile/).

The central role of revising skills in any translation process, whether initiated by machines or translators, is also reflected in the European standard for translation services, EN 15038 (2006). Actions aimed at optimizing a target text appear three times in the standard, first as "checking" (one's own work), then as "revising" (someone else's work, on the basis of both ST 
and TT), as "reviewing" (someone else's work, on the basis the TT only), and, finally, as "proofreading" (a final check of a document before it goes to print). (See Biel's [2011] insightful discussion of this standard for a distinction between the roles of checker, reviser, reviewer, and proofreader).

EN 15038 defines the revision of a translation by a translator knowledgeable in both languages involved as an obligatory element of the translation process, a development that Biel describes as follows: "It is the requirement of obligatory third-party revision that is of historic significance to the translation industry" $(2011,67)$.

The European standard underlines the importance of revision-by-translator in the context of achieving high quality target texts and points to a notion of quality, where style, coherence, and other elements that go beyond a good-enough approach matter. In an article on translators in the European Union, the German Süddeutsche Zeitung pointed out the fact that German parliamentarian were not satisfied with the quality of the German in translations into this target language (Winter 2012), indicating that users do indeed care about the quality of translations. (The same article also stressed the difficulties that the European Commission is facing in trying to find qualified [native] English-language translators.)

One of the key questions here is, of course, whether full post-editing (Rico and Torrejon 2012: 168) of MT output can be compared with revising the work of fellow translators. Frankly, I do not know, nor have I seen comparative studies that would allow for a clear answer to this question. Based on anecdotal evidence from one of my own translation practice classes, where I compared the revisions done for a total of 40 texts (German to English, 400 words average, informative texts, four on economic relations, four on wind energy) carried out by five advanced students (three native speakers of English, two native speakers of German with near-native English) with the revisions done to Google Translate (GT) outputs for the same source texts, I would venture to claim that many of the corrective measures are quite similar indeed (mainly syntactic reorganization, introduction of cohesive devices, clarification of information), with clear advantages for GT in terms of terminology (both in terms of precision and consistency) and formal aspects such as spelling and punctuation. However, these anecdotal impressions would probably have been quite different for different text types and subject areas or the reversed language direction (not to speak of different language combinations). There is clearly room for research here.

Independent of whether post-editing and revising can be compared, both approaches-MT and translation (no I am not going to add "human" just yet)—benefit from feeding the results of any revisions back into the translation production process. Tim Martin from the European Commission's Directorate-General for Translation stresses the importance of feedback "that allows its results to be channelled back into the whole cycle of translation production in order to eliminate or reduce problems at source" (2007: 62). The same goes of course for MT systems, where feedback is generally referred to as "training," an activity that focus to a large extent on the addition of terminology (see Thicke 2011 for an example of the positive impact of terminology on MT quality and post-editing productivity), which brings me to the second meta-skill, that of documentary research.

\subsection{Documentary research skills}

Both EN 15038 and the EMT initiative list research skills ("information mining") as an essential translation competence-as do other competence models (cf. PACTE). In addition to being an independent competence, the ability to efficiently research, evaluate, and apply information, i.e. information literacy (see Pinto Molina and Sales Salvador 2008a and 2008b), supports all other competences (if you prefer a componential approach) or the one two-fold translation meta competence that Pym describes as "[t]he ability to generate a series of more than one viable target text (TTI, TT2 ... TTn) for a pertinent source text (ST); [and] "t]he ability 
to select only one viable TT from this series, quickly and with justified confidence" (2003: 489).

Pym does not explain how the generation of possible translation solutions comes about or how it can be supported by external resources but it is safe to assume that researching information to complement a translator's existing textual and word knowledge plays a significant role in this process (as do viable target texts proposed by translation memory or machine translation systems, which discourage an active participation in the generation process on the part of the translators but might nevertheless provide useful and didactically meaningful TT alternatives). The use of the internet as a reference work and the idea of the Web as Corpus (WaC, see Austermuehl 2012 for a detailed discussion) not only aid in the generation of translation options or hypotheses, but also help translators decide which options to select (by checking frequencies, triangulating different sources, checking the reliability of a source, etc.). Translation decisions that are based on thorough background research and corpus queries might, however, be in conflict with the content provided by existing translation memories or termbases that "favour the authoritative elimination of alternatives" (Pym 2003: 494) and thus restrict the decision power of well-informed translators. This "over-use of TMs," warns Dorothy Kenny, drawing on Bédard (2000), "could lead to the deskilling and demotivation of translators" (2007: 204).

While, as Enríquez Raído points out with regard to Spain, "the importance of acquiring information literacy in translator training has long been recognized by the teaching community" (2011: 60), her research on the web searching behavior of translation students also shows that there is significant room for improvement when it comes to integrating online resources into the training for translators. In particular, Enríquez Raído underlines "the importance of teaching translation students-early on in the curriculum-(a) the diversity of (online) resources available for translation and (b) how to select adequate resources based on different types of problems, or information needs" (70-71).

The need for greater information literacy among translators is also reflected in the competence grid developed by the European Master's in Translation (EMT) expert group, In the Information Mining category of their model, the group lists the following sub-competences:

- Knowing how to identify one's information and documentation requirements

- Developing strategies for documentary and terminological research (including approaching experts)

- Knowing how to extract and process relevant information for a given task (documentary, terminological, phraseological information)

- Developing criteria for evaluation vis-à-vis documents accessible on the internet or any other medium, i.e. knowing how to evaluate the reliability of documentary sources (critical mind)

- Knowing how to use tools and search engines effectively (e.g. terminology software, electronic corpora, electronic dictionaries)

- Mastering the archiving of one's own documents (EMT Expert Group 2009: 6)

In the context of this article, the second-to-last skill set is crucial, and underlines the importance of being able to manipulate large sets of data and to extract terminological information from them and make it available in a flexible and sustainable way. One interesting question with regard to terminology research will be whether individual freelance translators will move towards on ad-hoc approach to terminography that favors quick online queries over the more cumbersome practice of termbase creation and maintenance (see Bowker 2011) 
and whether termbases will be reduced to the provision of training data for MT systems (see Melby 2012). The latter would, in my mind, be a problematic development, as well-maintained terminology databases are clearly more than simple glossaries and represent a rather crucial information management and knowledge generation tool.

Documentary research skills directly support the first meta-competence discussed above, that of revising. The ability to gather background knowledge and identify reliable terminological and phraseological information and the ability to effectively and sustainably manage that information in databases), which have traditionally played an important role in translation programs, will also allow translators to improve the quality, to refer back to EN 15038, of their checking, revising, reviewing, and proofreading skills, and will, in my mind, contribute to closing the gap between native and non-native speakers

\section{Conclusion}

I studied translation myself not to become a translator but to enter a career in journalism, and my approach to translation, and to translation competence, is still very much influenced by that original interest in being able to actively gather, process, and apply information coming from a variety of sources to create a well-written, functioning text. For me, knowing how to use technology to support this goal of producing a high-quality end product should be at the core of translator training and should be integrated into our curricula as early as possible, and does not even have to be taught within a dedicated technology course. The development of these skills does not have to be relegated to a separate course as they usually are already part of the skills set of translation trainers or could be developed through targeted trainer-thetrainer seminars. In principle, the same applies to CAT tools such as terminology databases and terminology managements systems, although here attitudinal and aptitudinal resistance might be greater.

Looking back at my studies at the University of Heidelberg, which were mostly technology free for the first two years, two of the course that I found most relevant were Grundsprachliche Kompetenzerweiterung (a kind of German for Germans, taught by Klaus Lothholz) and a course on foreign-language text production, taught by Andrew Jenkins, in which we discussed and revised target texts, without access to the respective source texts (see Jenkins 1995). In a way, the latest technological developments in translation technology might actually lead us back to the basics in translation (technology) training reminiscent of pre-CAT times-ironic...

\section{References}

Atkinson, D. P. (2011). Freelance translator success and psychological skill: a study of translator competence with perspectives from work psychology. Auckland: Centre for Translation Studies and Interpreting. The University of Auckland.

Austermuehl, F. (2001). Electronic tools for translators. Manchester: St. Jerome.

(2011). "On clouds and crowds - current developments in translation technology. T21N ". Translation in Transition 9/2011. <http://www.t21n.com/homepage/articles/T21N2011-09-Austermuehl.pdf>. Accessed 04.10.13.

(2012). "Using concept mapping and the web as corpus to develop terminological competence among translators and interpreters". Translation Spaces, 1 (1): 54-80.

Biel, L. (2011). "Training translators or translation service providers? EN 15038:2006 standard of translation services and its training implications". The Journal of Specialised Translation (16): 61-76. 
Bowker, L. (2011). "Off the record and on the fly". In: Kruger, A., Wallmach, K. and Munday, J. (eds.). Corpus-based translation studies: research and applications. London: Continuum, p. 211-236.

CIUTI. Profile.<http://www.ciuti.org/about-us/profile/>. Page consulted on date: 01.10.13.

De Palma, D. and Kelly, N. (2008). Translation of, for, and by the people: how user-translated content projects work in real life. Lowell, Mass: Common Sense Advisory.

Désilets, A. (2010). Collaborative translation: technology, crowdsourcing, and the translator perspective. Paper read at AMTA 2010, at Denver, Colorado, USA. <www.mtarchive.info/AMTA-2010-Desilets.pdf>.

Doherty, S. and J. Moorkens (2013). "Investigating the experience of translation technology labs: pedagogical implications". The Journal of Specialised Translation (19):122-136.

Doherty, S.; Kenny, D. and Way, A. (2012). Taking statistical machine translation to the student translator. Paper read at The Tenth Biennial Conference of the Association for Machine Translation in the Americas, at San Diego: California. $<$ http://doras.dcu.ie/17669/1/AMTA-2012-Doherty-1.pdf>.

EMT Expert Group. (2009). Competences for professional translators, experts in multilingual and multimedia communication.

<http://ec.europa.eu/dgs/translation/programmes/emt/key_documents/emt_competences _translators_en.pdf>. Page consulted on date: 01.10.13.

Enriquez Raido, V. (2011). "Developing web searching skills in translator training". Revista Electrónica de Didáctica de la Traducción y la Interpretación, 6: 55-77.

Enriquez Raido, V. and Austermühl, F. (2003). "Translation, localization, and technology current developments". In: Pérez-González, L. (ed.). Speaking in tongues: language across contexts and users. Valencia: University of Valencia Press, p. 225-250.

European Committee for Standardization. (2006). EN 15038:2006 Translation servicesService requirements. Brussels.

González Davies, M. (2004). Multiple voices in the translation classroom: activities, tasks and projects. Amsterdam; Philadelphia: John Benjamins.

Green, S.; Heer, J. and Manning, C. D. (2013). The efficacy of human post-editing for language translation. Paper read at Proceedings of the SIGCHI Conference on Human Factors in Computing Systems, CHI 2013, at Paris, France, p. 439-448. $<$ http://vis.stanford.edu/files/2013-PostEditing-CHI.pdf>.

Hutchins, J. (2005). "Current commercial machine translation systems and computer-based translation tools: system types and their uses". International Journal of Translation. 1-24.

Jenkins, A. (1995). "Teaching German translation students German-English translation". Realities of Translating. anglistick \& englischunterricht, 55/56.: 73-91.

Kelly, D. (2005). A handbook for translator trainers: a guide to reflective practice. Vol. 10, Translation practices explained. Manchester: St. Jerome.

(2007). "Translation memories and parallel corpora: challenges for the translation trainer". In: Kenny, D. and Ryou, K. (eds.). Across boundaries: international perspectives on translation. Newcastle-upon-Tyne: CSP, p. 192-208.

Kenny, D. (2007). "Translator competence contextualized. Translator training in the framework of higher education reform: in search of alignment in curricular design". In: Kenny, D. and Ryou, K. (eds.). Across boundaries: international perspectives on translation studies. Newcastle: Cambridge Scholoar Publishing, p. 128-142. 
Kenny, D. and Way, A. (2001). Teaching machine translation \& translation technology: a contrastive study. Paper read at MT Summit VIII Workshop on Teaching Machine Translation, at Santiago de Compostela, Spain, p. 13-17. <http://doras.dcu.ie/15830/1/Teaching_Machine_Translation_\%26_Translation_Technolo gy.pdf>.

Kiraly, D. C. (2000). A social constructivist approach to translator education: empowerment from theory to practice. Manchester: St. Jerome.

Koehn, P. (2009). "A process study of computer aided translation". Mach Translat, 23: 241263.

Koehn, P. (2010). Statistical machine translation. New York: Cambridge University Press.

Lafeber, A. (2012). "Translation skills and knowledge - preliminary findings of a survey of translators and revisers working at inter-governmental organizations". Meta: Translators' Journal, 57 (1): 108-131.

Luhman, B. (1998). Everybody's free to wear sunscreen. Last updated: 24.05.07. <http://www.youtube.com/watch?v=sTJ7AzBIJol>. Page consulted on date: 01.10.13.

Martin, T. (2007). "Managing risks and resources: a down-to-earth view of revision". JoSTrans, The Journal of Specialised Translation, 8: 57-63.

Melby, A. K. (2012). "Terminology in the age of multilingual corpora". The Journal of Specialised Translation (18): 7-29.

Mossop, B. (2001). Revising and editing for translators. Manchester: St. Jerome.

Moyer, D. 2007. Satisficing. Harvard Business Review.<http://hbr.org/2007/04/satisficing/ar/1>

Moyer, D. (2007). Optimizing, the art of finding the best choice among all choices, is a luxury we can seldom afford. Last updated: 01.04.07. <http://hbr.org/2007/04/satisficing/ar/1>. Page consulted on date: 01.10.13.

O'Brien, S. (2002). Teaching post-editing: a proposal for course content. Paper read at 6 th EAMT Workshop Teaching Machine Translation, at Manchester, p. 99-106.

(2006). "Pauses as indicators of cognitive effort in post-editing machine translation". Across Languages and Cultures, 7 (1): 1-21.

Olvera Lobo, M. D.; Robinson, B.; Castro Prieto, R. M.; Quero Gervilla, E.; Munoz Martin, R.; Munoz Raya, E.; Murillo Melero, M.; Senso Ruiz, J. A.; Vargas Quesada, B. and Diez Lerma, J. L. (2007). "A professional approach to translator training (PATT)". Meta, 52 (3): 517-528.

OPTIMALE. The OPTIMALE employer survey and consultation. < http://www.translatortraining.eu/attachments/article/52/WP4_Synthesis_report.pdf>. Page consulted on date: 01.10 .13

Pinto Molina, M. and Sales Salvador, D. (2008a). "INFOLITRANS: A model for the development of information competence for translators". Journal of Documentation, 64 (3): 413-437.

(2008b). "Towards user-centred information literacy instruction in translation: the view of trainers". Interpreter and Translator Trainer, 2 (1): 47-74.

Pym, A. (2003). "Redefining translation competence in an electronic age. In defence of a minimalist approach". Meta: Translators' Journal, 48 (4): 481-497. 
(2011). Democratizing translation technologies - the role of humanistic research. Paper read at The Luspio Translation Automation Conference, at Rome.

. (2012). Translation skill-sets in a machine-translation age. Last updated: 05.2012. $<$ http://usuaris.tinet.cat/apym/on-line/training/2012_competence_pym.pdf $>$. Page consulted on date: 23.09.13.

Rico, C. and Torrejon, E. (2012). "Skills and profile of the new role of the translator as MT post-editor". Tradumatica, 10: 166-178.

Sales Salvador, D. and Pinto Molina, M. (2008). "Knowledge transfer and information skills for student-centered learning: some academic experiencies in Spain". Portal: libraries and the academy, 8 (1): 53-74.

Schmich, M. (1997). Advice, like youth, probably just wasted on the young. Last updated: 01.06.1997. <http://www.chicagotribune.com/news/columnists/chi-schmich-sunscreencolumn,0,5909206,full.column>. Page consulted on date: 01.10.13.

Specia, L.; Raj, D. and Turchi, M. (2010). "Machine translation evaluation versus quality estimation". Mach Translat, 24: 39-50.

Thicke, L. (2011). "Improving MT results: a study". MultiLingual, 22 (1): 37-40.

Vermeer, H (1986). Voraussetzungen für eine Translationstheorie: einige Kapitel Kultur- und Sprachtheorie. Heidelberg: Vermeer.

Way, A. (2009). "A critique of statistical machine translation". Linguistica Antverpiensia, 8/2009 (Special issue on Evaluation of Translation Technology), p. 17-41.

Way, A. and Hearne, M. (2011). "On the role of translations in state-of-the-art statistical machine translation". Language and Linguistics Compass, 5 (5): 227-248.

Wikipedia. Satisficing. <http://www.princeton.edu/ achaney/tmve/wiki100k/docs/Satisficing.html>. Page consulted on date: 01.10.13.

Winter, M. (2012). "Es fehlt an der Sprache". Süddeutsche Zeitung.<http://sz.de/1.1435076>.

Zetzsche, J. (2007). "Creating the ideal word processing environment in translation environment tools". Translation Journal 11 (4).

$<$ http://www.translationdirectory.com/articles/article1504.php>. Page consulted on date: 04.10.13.

(2012). "Translation technology comes full circle". MultiLingual, April: 50-51. 